\title{
Investing in acute health services: is it time to change the paradigm?
}

Rhonda Kerr ${ }^{1,2}$ BA.(Econs) GAICD, University Associate

Delia V Hendrie ${ }^{1}$ BSc, BA, MA, GrDiplApplFin, GrDiplRoadSafety Senior Research Fellow

Rachael Moorin ${ }^{1}$ PhD, GradDipHIthEcon, MSc. Associate Professor, Adjunct Associate Professor

School of Population Health, University of Western Australia

${ }^{1}$ Centre for Population Health Research, Faculty of Health Science, Curtin University, GPO Box U1987, Perth, WA, 6845, Australia. Email:Delia Hendrie D.V.Hendrie@curtin.edu.au; Rachael Moorin R.Moorin@curtin.edu.au²Corresponding author.Email: kerr005@bigpond.com

\section{Abstract}

Objective: Capital is an essential enabler of contemporary public hospital services funding hospital buildings, medical equipment, information technology (IT) and communications. Capital investment is best understood within the context of the services it is designed and funded to facilitate. The aim of the study was to explore the information on capital investment in Australian public hospitals and the relationship between investment and acute-care service delivery in the context of efficient pricing for hospital services

Methods: This paper examines the investment in Australian public hospitals relative to the growth in recurrent hospital costs since 2000-01 drawing from the available data, the grey literature and the reports of six major reviews of hospital services in Australia since 2004.

Results: While the average annual capital investment over the decade from 2000-01 represents 7.1\% of recurrent expenditure on hospitals, the most recent estimate of the cost of capital consumed delivering services is $9 \%$ per annum. Five out of six major inquiries into healthcare delivery required increased capital funding to bring clinical service delivery to an acceptable standard. The sixth inquiry lamented the quality of information on capital for public hospitals. In 2012-13 capital investment was equivalent to $6.2 \%$ of recurrent expenditure, $31 \%$ lower than the cost of capital consumed in that year.

Conclusions: Capital is a vital enabler of hospital service delivery and innovation but there is a poor alignment between the available information on the capital investment in public hospitals and contemporary clinical requirements. The policy to have capital included in activity based payments for hospital services necessitates an accurate value for capital at the Diagnosis Related Group (DRG) level relevant to contemporary clinical care, rather than the replacement value of the asset stock.

What is known about the topic? Deebles' comprehensive hospital-based review of capital investment and costs, published in 2002, found that investment averages of between $7.1 \%$ and $7.9 \%$ of recurrent costs primarily replaced existing assets. In 2009 the Productivity Commission and the National Health and Hospitals Reform Commission (NHHRC) recommended capital, for the replacement of buildings and medical equipment, be included in activity based funding. But there have been persistent concerns about the reliability and quality of the information on the value of hospital capital assets. 
What does this paper add? This is the first paper for over a decade to look at hospital capital costs and investment in terms of the services they support. While health services seek to reap dividends from technology in healthcare, this study demonstrates that investment relative to services costs has been below sustainable levels for most of the last 10 years. The study questions the helpfulness of the highly aggregated information on capital for public hospital managers striving to improve on the efficient price for services.

What are the implications for practitioners? Utilizing specific and accurate information on capital allocations at Diagnosis Related Group (DRG) level, assists health services managers advance their production functions for the efficient delivery of services.

\section{Introduction}

Australian hospitals strive to meet the challenge of delivering high-quality clinical care, technological innovation with expanding patient demand and enhanced efficiency. Capital investment in hospital buildings, equipment and systems aims to facilitate best practice care at the time of the investment. But while the gold standard for hospital design is 'for form to follow function'(Sullivan 1896), it is also true that form follows finance. So this paper considers the relationship between the recurrent costs associated with delivering public hospital services and capital investment using published information, including the reports of six significant reviews of hospital services since 2004.

The Productivity Commission estimates that the annual cost of capital consumed providing hospital services is equivalent to $9 \%$ of recurrent expenditure(Steering Committee for the Review of Commonwealth/State Service Provision (SCRCSSP) 2013) which is greater than the average annual capital investment over the decade from 2000-01 of 7.1\% of recurrent expenditure.(AlHW 2012a) In 2012-13 capital investment was equivalent to $6.2 \%$ of recurrent expenditure, $31 \%$ lower than the cost of capital consumed in that year.

From the findings of two national hospital reviews and four state-based reviews regarding the published estimates of capital investment and costs, it is evident that there is poor alignment between the available information on capital investment in public hospitals and contemporary clinical requirements.

Five out of six major inquiries into healthcare delivery required increased capital funding to bring clinical service delivery to an acceptable standard. The sixth inquiry lamented the quality of information on capital for public hospitals. Aggregated data on capital investment is not servicespecific or sufficiently sensitive to contemporary clinical requirements to be a useful tool for health managers pursuing the efficient price for services.(Young D W Pearlman L K 1993; Vogl M 2014; Duckett S 1994)

In 2010-11 Australia spent $\$ 130.26$ billion on healthcare of which $\$ 38.4$ billion was for recurrent expenditure in public hospitals and $\$ 4.2$ billion, or $3.2 \%$, was for capital expenditure. The expenditure on public hospitals represented $3.6 \%$ of Australia's gross domestic product (GDP) and investment in these hospitals was $0.35 \%$ of GDP.(AlHW 2012b)

Judging the appropriate level for healthcare investment is of importance for our community, clinicians and politicians. Access to sufficient hospital beds and appropriate diagnostic and treatment facilities permits clinicians to effectively manage growing demand from populations with increasing 
chronic disease and an expanding demand for hospital care.(Steering Committee for the Review of Commonwealth/State Service Provision (SCRCSSP) 1999) While debates continue on the correct number of beds, the discussion of capital funding for the broader range of treatment and accommodation services has been lacking. Over recent years major inquires have identified problems and challenges in the relationship between capital investment and hospital service delivery. ${ }^{10-14}$ Yet little is published on capital investments for healthcare and it has been acknowledged that estimates of the value of capital for healthcare and the appropriate level of investment in public healthcare are difficult to establish. (Steering Committee for the Review of Commonwealth/State Service Provision (SCRCSSP) 1999; Productivity Commission 2009; Steering Committee for the Review of Government Service Provision (SCRGSP) 2001; Deeble J 2002; Steering Committee for the Review of Commonwealth/State Service Provision (SCRCSSP) 1997, 1998)

The present study examines published information on the investment in Australian public hospitals and how that investment relates to the acute service delivery it is required to facilitate.

\section{Methods}

The study used qualitative methods to review recent literature on capital investment in the healthcare sector and quantitative methods to assess levels of capital investment.

\section{Literature review}

Electronic bibliographic databases (Emerald, Medline, ProQuest) were searched for Australian literature published between 1980 and April 2013 on capital in healthcare using the keywords: Australia (n), capital, capital investment and acute healthcare, hospitals and infrastructure, and hospital building.

\section{The grey literature}

References to capital were found in six major health reviews, including the National Health and Hospitals Reform Commission (NHHRC) Interim and Final Reports (NHHRC 2008, 2009) and the Productivity Commission Research Study into Public and Private Hospitals,(Productivity Commission 2009) the Garling Royal Commission in NSW,(Garling P 27 November 2008) the Forster Review in Queensland,(Forster P 2005) the Reid Review in WA(Reid M 2004) and Stokes Report on the 4 hour rule in WA,(Stokes B 2011) the Reports on Government Services prepared by the Industry Commission (1993-97) and the Productivity Commission (1998-2013) were also examined.

\section{Data collection}

Data on recurrent and capital expenditure in the health sector were obtained from Hansards for Commonwealth, State and Territory Parliaments and Budget Papers for 2012-13 for each Australian jurisdiction.(Swan W.(AustralianTreasurer) 2012; Wells K (Victorian Treasurer ) 2012-13; Baird M (NSW Treasurer) 2012b, 2012a; Nicolls T (Queensland Treasurer) 2012; Snelling J (SA Treasurer) 2012; Porter C (WA Treasurer) 2012; Giddings L (Tasmanian Premier \&Treasurer) 2012; Lawrie D (NT Treasuer) 2012; Barr A ( ACT Treasurer) 2012) In most instances Commonwealth funding for hospitals included in state and territory budgets were extracted to prevent double counting. Expenditure data on healthcare was also extracted from the Productivity Commission and Australian Institute of Health and Welfare (AIHW) publications. (AlHW 2012b) 


\section{Analysis}

Statements on the value of capital, recommendations and actions in relation to necessary investments and issues of access to capital from the major reviews of health services and hospital services were extracted for analysis. Comparative historical data on public hospital recurrent and capital expenditure for buildings and equipment was drawn from AlHW publications and state and territory budget papers with capital expenditure specifically on hospitals calculated as a percentage of recurrent expenditure.(Steering Committee for the Review of Commonwealth/State Service Provision (SCRCSSP) 2013, 1999, 1997, 1998, 2001) (Steering Committee for the Review of Commonwealth/State Service Provision (SCRCSSP) 2001) Similarly, data on indicative capital cost and recurrent expenditure per case mix adjusted separation for each state and territory was drawn from each of the Reports on Government Services for 2010-13 and expressed as a percentage for comparison with results from an earlier study(Steering Committee for the Review of Governemnt Service Provision (SCRGSP) 2010).

\section{Capital alignment with hospital services}

The literature review identified only one comprehensive study costing capital for Australian public hospitals. Deeble's national study found the built capital investment for similar patient treatments varied by up to $70 \%$ per bed within two large state systems, noting greater endowments in major teaching hospitals for built capital and equipment. He was concerned that centralised systems for rationing capital were 'increasingly questioned on efficiency grounds'(Deeble J 2002)p. 53) with decision-making that was doubtful in terms of data and technique and lacked transparency(Deeble J 2002). Commenting on the irregularity and evident 'lumpiness' of investment in hospitals, Deeble identified that 'many health administrators see capital allocation... as a competition for funds whose total is fixed by some unfathomable budget process in which political sensitivity, historical precedent and rules of thumb are as important as demonstrated need.'(Deeble J 2002)p.53).

Similarly, the Australian Industry Commission (1993-97) later the Productivity Commission (19982003), in their annual Reports on Government Services expressed concern about the valuations of public hospital capital described as 'indicative', 'difficult 'and 'unreliable' (Steering Committee for the Review of Commonwealth/State Service Provision (SCRCSSP) 1999, 1998, 1997; Steering Committee for the Review of Government Service Provision (SCRGSP) 2000).

Subsequently, state and national reviews of health service delivery between 2004 and 2011 have commented on the adequacy of capital allocations for hospitals to achieve an acceptable standard of care (Table 1)(Productivity Commission 2009; NHHRC 2008, 2009; Reid M 2004; Forster P 2005; Garling P 27 November 2008; Stokes B 2011).As Table 1 shows, the four state-based reviews into the quality, efficiency and delivery of hospital services found that clinical service delivery was affected by capital allocation. Similarly the NHHRC found that additional capital expenditure was required to achieve clinical service improvement. (NHHRC 2009)The Productivity Commission Report compared the prices of services between the private and public hospital sectors by DRG, estimating capital to be more expensive in the public sector(Productivity Commission 2009).

While initially valuing capital as one large historically based asset, in reviewing the evidence most reviews discussed the issues surrounding built, and medical equipment capital independently, and IT and communications capital as separate productive elements required to deliver contemporary 
care(Productivity Commission 2009; NHHRC 2009; Forster P 2005; Garling P 27 November 2008; Stokes B 2011).Only Stokes examined the patient flow and clinical functions and then used capital as a support for improving the efficiency of clinical activity(Stokes B 2011).

Table 1 shows how capital for public hospital services was valued by the reviews, the outcomes of the reviews for investment in buildings, equipment and IT and communications, and identified issues relating to the process of accessing capital. Each of the reviews of clinical service delivery advocated for additional capital for hospitals, with the exception of Queensland and the technically focused Productivity Commission review(Productivity Commission 2009; NHHRC 2009; Reid M 2004; Forster P 2005; Garling P 27 November 2008; Stokes B 2011).

Table 1 Australian Health Service Delivery Reviews 2004-2011: Commentary on public hospital capital allocation 


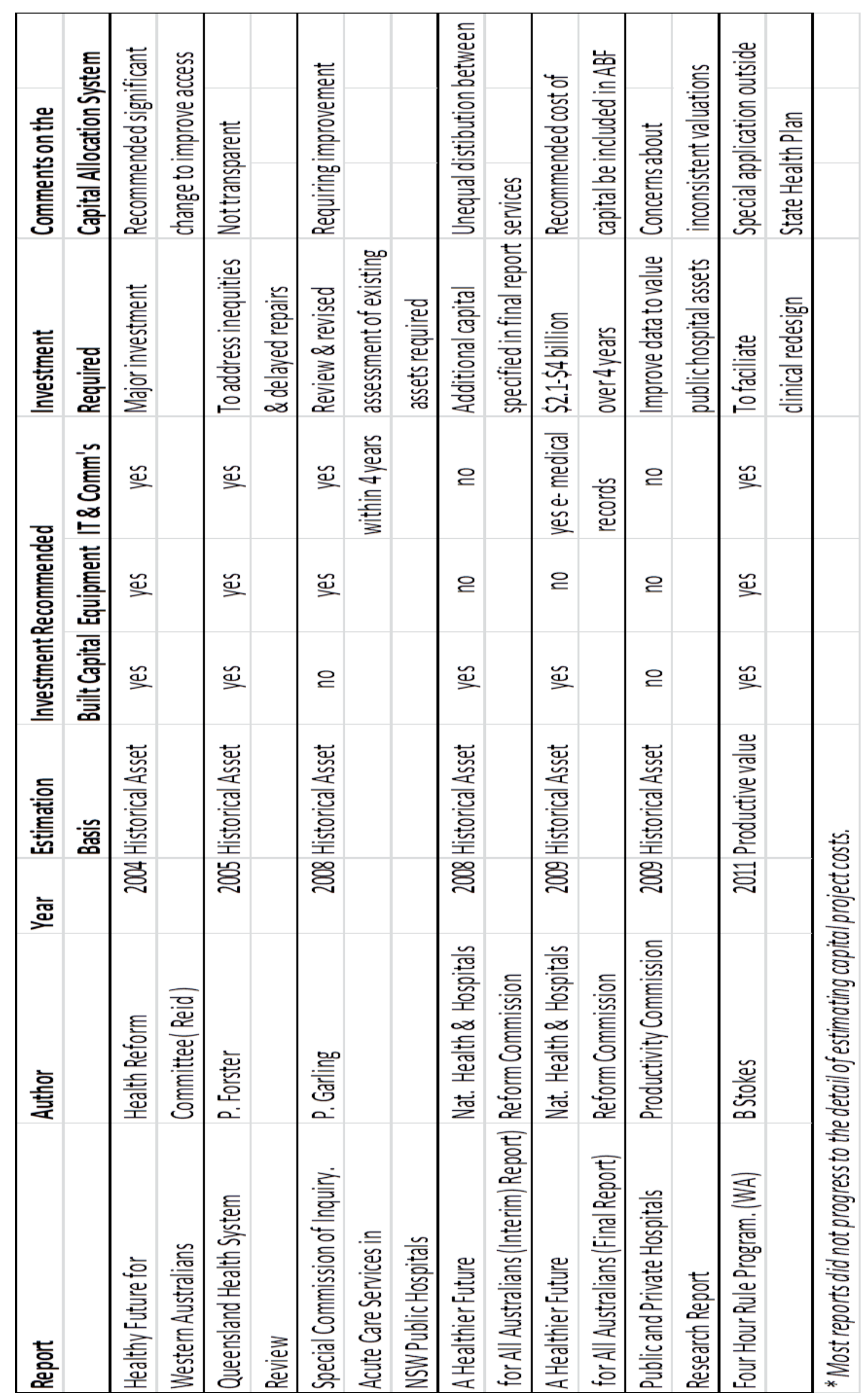


As the last column of Table 1 shows, systemic problems in allocating capital were identified in NSW and Queensland and by the NHHRC with the Productivity Commission also expressing dissatisfaction, at a national level, with inconsistencies with the valuation of public hospital capital, depreciation, and for valuation of leases and public-private partnerships. More specifically:

- The Forster Review reported the Queensland health system as 'being under significant pressure with insufficient resources to meet increasing demand'.(Forster P 2005)page 268). The inadequate supply of capital infrastructure resulting in insufficient beds was regarded as deficient, with funding for asset replacement, refurbishment, maintenance and building operation as significant issues. The NHHRC also noted the need to maintain, replace and repair existing capital(Forster $P$ 2005). Forster identified that decision making on capital was remote from the clinical services, unequal and that 'securing adequate levels of funding for the capital works program has been problematic.'(Forster $\mathrm{P}$ 2005)p. 42) Inequality in the distribution of capital between clinical services was also noted by the NHHRC.(NHHRC 2008)

- In NSW the Garling Royal Commission of review into hospital services also found a system struggling to deal with increased demand for care. The Commissioner noted: 'In an industry where the state of equipment correlates closely to patient safety, it is important to routinely review the equipment in use and plan for the replacement of equipment as it comes to the end of its useful life or becomes unsuitable for use in the safe, modern practice of medicine. As a piece of equipment nears the end of its useful life, I would expect to see the cost of a replacement machine being factored into the budget of the hospital, so that it could be sourced and funded without interrupting clinical activities. This does not seem to be happening at all.'(Garling P 27 November 2008)p. 1033). Similar comments were made about difficulties with investment in IT, (Garling P 27 November 2008)p. 7) and communications, access to imaging (Section 1.175), beds (p. 30), emergency departments, intensive care unit beds and operating theatres (Section 1.172-3)(Garling P 27 November 2008).

- In WA the 2004 Reid Review addressed concerns about fiscally unsustainable costs to operate the hospitals' averaging increases of $8.5 \%$ per annum. Major investment in new hospitals and significant expansions of metropolitan hospitals were among the key enablers for making the hospitals more efficient(Reid M 2004).

- In a review of the operation of the four-hour emergency department rule in Perth hospitals in 2011, Stokes noted that the processes of clinical redesign in both the UK and Western Australia had been characterised by a change in vision, improving the quality of care and focussing on patients. Capital to modify buildings, improve communications and IT and buy medical equipment was required to achieve the changes necessary for the four-hour rule to operate effectively. He noted that the success of clinical redesign in the UK involved a $\mathrm{f600}$ million investment in infrastructure and support(Stokes B 2011).

- In 2002 Deeble's findings (Deeble J 2002)from his detailed state-based studies were similar to these five public inquiries, that not all hospitals providing treatments for similar patients are equally endowed in buildings or equipment for acute service delivery(NHHRC 2008, 2009; Reid M 2004; Forster P 2005; Garling P 27 November 2008; Stokes B 2011). 
On a broader scale, after extensively reviewing the health sector in 2009 the NHHRC questioned if the amount of capital investment was correct and identified capital as 'vital to reshaping how care is delivered, filling service gaps, building new systems and capabilities and stimulating change.'(NHHRC 2009)p. 168).

In a subsequent 2009 study the Productivity Commission compared the costs between public and private sector hospitals and estimated the cost of capital for most DRGs. Since it affirmed NSW Health's view that 'nobody knows exactly how much capital is currently used by public hospitals', (NHHRC 2009)p. 303) approximations of the value of public hospital capital were required. The result was an estimation based on depreciation plus the user cost of capital (UCC) or the cost of the money rather than a clinically based system of capital estimation(NHHRC 2009). The authors used a regression analysis to distribute the total capital endowment into individual DRGs, implicitly assuming that all public hospitals have access to an equal stock of built and equipment capital(NHHRC 2009). This assumption contrasts with the finding of the reviews.

\section{Consistency of measurement}

Information on capital investment for hospitals in Australia is published at the state and territory level by the AIHW based on Australian Bureau of Statistics bi-annual surveys and extrapolations for intervening years(AIHW 2012a).

To estimate the capital consumed at the diagnosis level in the annual Report on Government Services, the Productivity Commission used the total state (or territory) values of capital depreciation plus the UCC as previously mentioned. The information is 2-3 years old when the reports are made. The Productivity Commission has expressed concerns about the quality of the deprecation information(Productivity Commission 2009).

In contrast, Deeble avoided depreciation values by pricing approximately 50000 equipment items and the functional areas of over 140 hospitals at contemporary replacement standards. Deeble drew from the asset registers of hospitals in five states and the ACT assessing replacement cost valuations for hospital buildings and equipment(Deeble J 2002).

\section{Levels of Public Hospital Investment}

Deeble, in a landmark hospital-based costing study,(Deeble J 2002) found that there was a near constant ratio of capital to recurrent expenditure over 40 years to 2000, with capital representing $7.1 \%$ to $7.9 \%$ of acute public hospital recurrent expenditure. Data from his detailed study of the capital elements of public hospitals showed that only $0.4 \%$ of capital expenditure was for growth or new services. Almost all capital expenditure on public hospitals was for the replacement and updating of existing assets.(Deeble J 2002)

Table 2 outlines the investment in public hospitals between 2000-01 and 2010-11 (in constant prices) compared with the generally steady growth of recurrent expenditure for public hospitals. Over the decade $2000-01$ to $2009-10$, capital averaged $7.1 \%$ of recurrent expenditure. The period 2000-01 to 2002-03 had capital investment, relative to recurrent expenditure, at between $7.1 \%$ and $7.4 \%$ rising to $7.5 \%$ in $2005-06$ to $2006-07$ after a sharp decline, to $4.9 \%$ and $6.6 \%$, in $2003-04$ and 2004-5. According to the standard set in Deeble's analysis, the funding between 2000-01 and 2007- 
08 falls below replacement level. It is only between 2008-09 and 2010-11 that the substantially increased investments in public healthcare and hospitals reached levels which support growth.

Table 2 Public Hospital Recurrent and Capital Expenditure, Australia, Constant Prices (a,) 2000-01 to 2010-11

\begin{tabular}{|lccr|}
\hline $\begin{array}{l}\text { Public } \\
\text { Hospital }\end{array}$ & Recurrent & Capital & \multicolumn{2}{c|}{$\begin{array}{l}\text { Capital \% } \\
\text { of } \\
\text { Recurrent } \\
\text { Year }\end{array}$} & $\begin{array}{c}\text { Expenditure } \\
\text { (\$ million) }\end{array}$ & $\begin{array}{c}\text { Expenditure } \\
\text { (\$ million) }\end{array}$ & \begin{tabular}{c} 
\% \\
\hline $\mathbf{2 0 0 0 - 0 1}$
\end{tabular} & $\mathbf{2 2 , 4 7 7}$ & 1,592 & 7.1 \\
$\mathbf{2 0 0 1 - 0 2}$ & 23,615 & 1,758 & 7.4 \\
$\mathbf{2 0 0 2 - 0 3}$ & 25,352 & 1,835 & 4.9 \\
$\mathbf{2 0 0 3 - 0 4}$ & 26,067 & 1,278 & 6.6 \\
$\mathbf{2 0 0 4 - 0 5}$ & 28,126 & 1,855 & 7.5 \\
$\mathbf{2 0 0 5 - 0 6}$ & 29,394 & 2,195 & 7.5 \\
$\mathbf{2 0 0 6 - 0 7}$ & 31,027 & 2,332 & 6.5 \\
$\mathbf{2 0 0 7 - 0 8}$ & 33,329 & 2,158 & 8.1 \\
$\mathbf{2 0 0 8 - 0 9}$ & 33,936 & 2,751 & 8.4 \\
$\mathbf{2 0 0 9 - 1 0}$ & 35,298 & 2,950 & 11.2 \\
$\mathbf{2 0 1 0 - 1 1}$ & 38,338 & 4,290 & \\
\hline
\end{tabular}

(a) Constant prices for 2000-01 to 2009-10 are expressed in terms of 2009-10 prices

Source: AlHW 2012. Health Expenditure Australia 2010-11. Tables 4.4 and 4.27

Table 3 presents data on the capital allocations for hospitals in 2012-13 Commonwealth, state and territory appropriation bills and budget papers. Capital investment includes new equipment and buildings, replacement of infrastructure and improvements to public hospitals(Wells K (Victorian Treasurer ) 2012-13; Baird M (NSW Treasurer) 2012a, 2012b; Nicolls T (Queensland Treasurer) 2012; Snelling J (SA Treasurer) 2012; NHHRC 2009; Porter C (WA Treasurer) 2012; Giddings L (Tasmanian Premier \&Treasurer) 2012; Lawrie D (NT Treasuer) 2012; Barr A ( ACT Treasurer) 2012). Capital allocations for hospitals in 2012-13 varied widely between states and territories, from $2.6 \%$ of recurrent expenditure in NSW to $25 \%$ in the ACT, with a national average of $4.9 \%$. Comparing Table 2 with Table 3 it can be seen that in 2012-13 total investment has returned to 2008-09 investment levels while recurrent expenditure has increased by $61 \%$ since that time. As a percentage of recurrent expenditure the 2013-14 funds allocated by states and territories returned to 2003-04 levels. 
Table 3 Capital Allocation for Public Hospitals as a Percentage of Recurrent Expenditure, 2012-13

\begin{tabular}{|lccr|}
\hline Public Hospital & $\begin{array}{c}\text { Recurrent } \\
\text { Expenditure } \\
\text { (\$ million) }\end{array}$ & $\begin{array}{c}\text { Capital } \\
\text { Expenditure } \\
\text { (\$ million) }\end{array}$ & $\begin{array}{c}\text { Capital \% } \\
\text { of Recurrent } \\
\%\end{array}$ \\
\hline NSW & 17,300 & 457 & 2.6 \\
Victoria & 13,684 & 480 & 3.5 \\
Queensland & 11,862 & 783 & 6.6 \\
South Australia* & 4,895 & 239 & 4.9 \\
Western Australia & 3,711 & 311 & 8.4 \\
Tasmania* & 1,331 & 161 & 12.1 \\
ACT* & 795 & 202 & 25.4 \\
Northern Territory & 1,229 & 50 & 4.1 \\
\hline Total & & & \\
& 54,805 & 2,684 & 4.9 \\
\hline
\end{tabular}

*Includes some National Health and Hospitals Fund grants

Source: State and Territory 2012-13 Budget Papers.

The Commonwealth, through the National Health and Hospitals Fund (NHH), has awarded $\$ 721.75$ million for public hospital improvements in 2012-13(Swan W.(AustralianTreasurer) 2012). The addition of NHH funds brings national capital expenditure for hospitals to $\$ 3.405$ billion or $6.2 \%$ of recurrent expenditure on health. However, this remains below the level of $8.3 \%$ of recurrent expenditure Deeble estimated as representing the replacement level.(Deeble J 2002) So only in the period 2009-11 has public hospital investment been above replacement levels.

The cost of capital consumed in providing acute health services

As previously mentioned the Productivity Commission's annual review of all government services has developed an indicative cost for capital consumed each year by major public hospitals. Table 4 shows the resulting estimates for capital consumed as a percentage of recurrent expenditure per case mix adjusted separation.

Nationally the capital consumed relative to the cost of case mix adjusted separation averaged between 9\% and 9.4\% but varied between low investment levels in Tasmania of 5.7\% in 2010-11 and $13.1 \%$ in Victoria in 2007-08. Significant challenges are evident for NSW, Victoria, South Australia and the territories with the consumption of capital at over $10 \%$ of their recurrent expenditure in 2010-11. An unequal pattern of capital consumption relative to recurrent costs is evident between states and territories. While Table 4 provides only indicative information at the separation level, it is the most detailed and specific information published on capital for Australian public hospitals. 
Table 4 Indicative Capital Cost per Casemix Adjusted Separation as a Percentage of Recurrent Cost per Casemix Adjusted Separation 2007-08 to 2010-11

\begin{tabular}{|cccccccccc|}
\hline & NSW & Vic & Q'Id & SA & WA & Tas & ACT & NT & Aust \\
\hline $\mathbf{2 0 0 7 - 0 8}$ & 10.1 & 9.2 & 13.1 & 8.2 & 9.8 & 6.8 & 10.4 & 10.6 & 9.3 \\
$\mathbf{2 0 0 8 - 0 9}$ & 10.3 & 10.2 & 10.9 & 8.5 & 9.9 & 7.4 & 9.8 & 9.1 & 9.1 \\
$\mathbf{2 0 0 9 - 1 0}$ & 10.0 & 12.7 & 9.9 & 11.3 & 9.5 & 6.2 & 9.4 & 12.0 & 9.4 \\
$\mathbf{2 0 1 0 - 1 1}$ & 10.3 & 11.9 & 8.4 & 10.4 & 8.5 & 5.7 & 10.7 & 11.8 & 9.0 \\
\hline
\end{tabular}

Source: Calculated from Report on Government Services 2010-2013Appendicies Tables 10.A59 \& 10A.61 of 2010, 10A.60 \& $10 A 58$ of 2011, 10A.53 \& 10A.55 of 2012, and 10A.52 \& 10A.54 of 2013

Similarly, AlHW estimates that the rate at which public healthcare services are consuming capital is increasing from an average year to year growth rate of 3.6\% between $2000-01$ and 2007-08 to $12.9 \%$ in 2008-09 and to $24.7 \%$ in 2009-10(AlHW 2011). Significant funds are required for the replacement of capital stocks consumed in delivering the rising number of services each year.

\section{Discussion}

The emerging picture of capital investment in Australian public hospitals from the literature and the data is that:

- The most recent indicative cost of capital consumed per separation is estimated by the Productivity Commission to average 9\% of recurrent costs in public hospitals in 2010-11 (Table 4)

- This estimate is higher than Deeble's calculation of capital consumption accounting for $8.3 \%$ of recurrent expenditure in 2002,(Deeble J 2002) but consistent with the AlHW estimates that replacement costs for the capital consumed in providing healthcare are rising significantly(AIHW 2011).

- These findings confirm that a sizable and growing level of capital expenditure is, and will continue to be, required to address the replacement of capital in public hospitals before new investments associated with growth, technological change or clinical redesign can be addressed.

- Yet the significantly increasing cost of asset replacement derives from two decades of investment in public hospital buildings and equipment which was, for all but 2 years, below replacement levels. So the available data makes clear that the capital stock of public hospitals has been consistently eroded over the past 20 years

In addition to the issue of the appropriateness of the total level of investment (relative to recurrent expenditure), there is an issue of the distribution of capital for similar patient services. Deeble found significant differences within states in the distribution of capital, particularly for medical equipment.(Deeble J 2002) Garling, Forster and the NHHRC also noted that the distribution of capital 
was not equal.(Garling P 27 November 2008; Forster P 2005; NHHRC 2009) Tables 3 and 4 also indicated appreciable differences in the total annual capital allocations of the states and territories; however, there is no more detailed information available on the investment in medical equipment, IT and buildings within states closer to the clinical service level.

The Productivity Commission, in its annual reports to government, comes closest to estimating what the indicative cost of capital per patient separation may be. However, the capital estimates remain based on the depreciated values of older assets rather than on the actual investment required to enable contemporary clinical care. High-value hospital investments of the past 40 years may not be the best predictors for the mix of future health equipment, IT and built assets required for clinical care. Indeed, Deeble argued that an 'allocation based on the present capital stock would simply perpetuate inequalities'.(Deeble J 2002)p. 54).

The NHHRC made clear that: 'Capital can drive change and is fundamental to achieving the efficiencies and reorientation of the health system we are recommending.'(NHHRC 2009)p. 168) Duckett and others have argued that in an activity-based funding environment, where the focus is on achieving quality care at the efficient price for each DRG, health managers require accurate and specific information on capital to facilitate efficient clinical services(Duckett S 1994; Vogl M 2014)

The National Healthcare Reform Agreement aims for Australians to have equitable access to highquality healthcare and access to transparent and nationally comparable information on hospitals. Responsibility for capital funding remains with the states and territories as capital is explicitly excluded from activity-based funding. So although recurrent funding for hospital services is focused on transparency and efficiency, capital funding arrangements remain largely unchanged.(Council of Australian Governments(COAG) 2011)

With a requirement to provide services at the efficient price, information on the investment in buildings, medical equipment and technology should support best-practice contemporary clinical care. From the available information and the quality of the data, it is apparent that capital funding flows do not share the objectives of transparency and efficiency embedded in the National Health Reform Agreement.

\section{Strengths and limitations of the study}

This is the first study to examine the level of investment in Australian public hospitals, drawing material from budget papers, the annual Reports on Government Services and all the major reviews into public hospital services since 2002. It provides a comprehensive overview of the information publicly available on capital invested in hospitals. It sets the information on capital in the context of the recurrent expenditure that capital is required to facilitate. This study builds on Deebles' 2002 paper.

Due to limitations of the data the study examines capital allocation for public hospitals only at the jurisdiction level rather than at hospital levels. Therefore, the information inherently generalises about the allocation of capital across a state or territory between hospitals. The reviews quoted had varying terms of reference and made conclusions based on submissions and analysis, some of which were not research-based. It has not always been possible to distinguish between hospital-based services and community care based at a hospital from the available information. Minor works capital 
provided through recurrent budgets also sits outside this analysis, as do charitable donations for the purchase of equipment in public hospitals. Capital costs associated with equipment leases and public-private partnerships for public hospitals include only funds allocated for capital purchases and do not include payments from recurrent allocations. The study is restricted to published information. The important issue of investment for clinical change and health service adaption have been only lightly addressed in this paper. The central issue of standards is the subject of another paper.

\section{Conclusions}

Capital is a vital enabler of hospital service delivery. Estimates of the annual cost of capital consumed in providing services are between $8.3 \%$ and $9.4 \%$ of recurrent hospital costs. However, the total investment in Australian public hospitals has averaged $7.1 \%$ of recurrent expenditure per annum over 10 years to 2009-10 (Table 2), shrinking to $6.2 \%$ of recurrent expenditure by 2012-13 (Table 3). It is evident that the investment in hospitals over all but 2 of the past 10 years has not kept pace with the growth in hospital services. Capital is being consumed faster than it is being replaced relative to the growth in hospital care.

The available information on capital for hospital services does not relate to service delivery or contemporary clinical care. It references the residual asset values and depreciation. Information on capital is not aligned to service provision or clinical care; it is not transparently focused on improving efficiency in clinical service delivery or on improving equity of access to high-quality clinical care. The available information to assess the adequacy of investment in public hospitals is aggregated at the state and territory level, blurring differences in the distribution of capital between hospitals and DRGs.

Five out of six major inquiries into healthcare delivery required increased capital funding to bring clinical service delivery to an acceptable standard.(NHHRC 2009; Reid M 2004; Forster P 2005; Garling P 27 November 2008; Stokes B 2011). The sixth inquiry lamented the quality of information on capital for public hospitals. (Productivity Commission 2009)

The policy to have capital included in activity-based payments for hospital services necessitates a real and accurate value for capital relevant to the delivery of efficient, contemporary clinical care, beyond the replacement value of the asset stock. Health service managers, clinicians and the community require access to meaningful information on investment and resource use in hospitals which supports their pursuit of greater efficiency and safety in patient care. Capital funding for hospitals should align with clinical requirements more strongly than with the replacement of aged assets.

\section{Competing interests}

None declared.

\section{Acknowledgements}

This paper is based on research as part of post-graduate studies at Curtin University, Bentley, Western Australia.

\section{References}


AlHW. 2011. "Health Expenditure 2009-10." Canberra: AlHW.

- - . 2012a. "Health Expenditure Australia 2010-11." Canberra: Health and Welfare Expenditure Series no. 47.

- - . 2012b. "Health Expenditure Australia 2010-11." Canberra: AlHW.

Baird M (NSW Treasurer). 2012a. "Appropriation Bills 2012-13." Sydney: NSW Government Treasury,.

- - . 2012b. "Infastructure Statement 2012-13 Budget Paper No. 4,." Sydney: NSW Government Treasury,.

Barr A ( ACT Treasurer). 2012. "Budget Paper No 4."

Council of Australian Governments(COAG). 2011. "National Health Reform Agreement." Canberra: COAG

Deeble J. 2002. "Capital Investment in Public Hospitals." Australian Health Review 25 (2): 45-57.

Duckett S. 1994. " Hospital and Departmental Management in the Era of Accountability: Addressing the New Management Changes. [Paper Presented at the Best Practice in the Health Sector Conference (1994)] " Australian Health Review 17 (3): 116-131.

Forster P. 2005. "Queensland Health Systems Review Final Report." Brisbane: Queensland Health,. Garling P. 27 November 2008. " Final Report of the Special Commission of Inquiry. Acute Care Services in Nsw Public Hospitals.", Sydney: NSW Government.

Giddings L (Tasmanian Premier \&Treasurer). 2012. "Budget Paper No 1- the Budget." Hobart: Government of Tasmania.

Lawrie D (NT Treasuer). 2012. "Budget Paper No 4. The Infrastructure Program,." edited by NT Department of Treasury and Finance, Darwin: Northern Territory Government.

NHHRC. 2008. "A Healthier Future for All Australians Interim Report December 2008." Canberra: National Health and Hospitals Reform Commission.

- - . 2009. "A Healthier Future for All Australians-Final Report of the National Health and Hospitals Reform Commission.", Canberra.

Nicolls T (Queensland Treasurer). 2012. "Queensland Government State Budget 2012-13 Capital Statement Budget Paper No3,." Brisbane: Queensland Treasury,.

Porter C (WA Treasurer). 2012. "2012-13 Budget Budget Statements ", Perth: WA Treasury Government of Western Australia,.

Productivity Commission. 2009. "Public and Private Hospitals: Productivity Commissin Research Report,." Melbourne: Productivity Commission,.

Reid M. 2004. "A Healthy Future for Western Australians. Report of the Health Reform Committee." Perth: Health Department of WA.

Snelling J (SA Treasurer). 2012. "2012-13 Budget Paper No 5 Capital Investment Statement Strong Foundations Stronger Future,." Adelaide: SA Government Department of Treasury and Finance,.

Steering Committee for the Review of Commonwealth/State Service Provision (SCRCSSP). 1997. "Report on Government Services ", Canberra: Productivity Commission,.

- - . 1998. "Report on Government Services ", Canberra: Productivity Commission,.

- - . 1999. "Report on Government Services ", Canberra: Productivity Commission.

- - . 2001. "Report on Government Services ", Canberra: Productivity Commission,.

- - - 2013. "Report on Government Services ", Canberra: Productivity Commission.

Steering Committee for the Review of Governemnt Service Provision (SCRGSP). 2010. "Report on Government Services." Canberra: Productivity Commission.

Steering Committee for the Review of Government Service Provision (SCRGSP). 2000. "Report on Government Services." Canberra: Productivity Commission.

- - - 2001. "Report on Government Services." Canberra: Productivity Commission,

Stokes B. 2011. "Four Hour Rule Program Progress and Issues Review,." East Perth: Health Department of WA, 
Sullivan, Louis. 1896. "The Tall Office Building Artistically Considered." Lippincotts Magazine The April Number: 403-409.

https://openlibrary.org/books/OL24600425M/The_tall_office_building_artistically_consider ed.

Swan W.(AustralianTreasurer). 2012. "Budget Speech 2012-13." Canberra: Australian Government Treasury,.

Vogl M. 2014. "Hospital Financing: Calculating Inpatient Capital Costs in Germany with a Comparative View on Operating Costs and the English Costing Scheme." Health Policy 115: 141-151.

Wells K (Victorian Treasurer ). 2012-13. "2012-13 State Capital Program, ." Melbourne: Treasury.

Young D W Pearlman L K. 1993. "Management Accounting in Hospitals: Lessons from Manufacturing " In Diagnosis Related Groups in Europe .Uses and Perspectives. , ed. Cases M \& Wiley MM, 113-129. Berlin: Springer- Verlag. 